\title{
Teacher Utilisation of Emergent Literacy Skills in the Teaching of Physical Education in the Primary Schools of Lundazi District
}

\author{
Tembo Beatrice ${ }^{1}$, Nyimbili Friday ${ }^{2}$, Namuyamba Mubita ${ }^{3}$, Tambulukani Geoffrey ${ }^{4}$ \\ ${ }^{1}$ Graduate in Masters of Applied Linguistics from UNZA, Education administrator, researcher, teacher of \\ literacy and language in Zambia. \\ ${ }^{2}$ PhD Student (Applied Linguistics) University of Zambia, Part time lecturer at University of Africa, Teacher of \\ English \& Physical Education - Lundazi, Zambia. \\ ${ }^{3}$ PhD candidate in Adult Education (UNZA), Part time Lecturer at Extension Studies Department of Adult \\ Education, Ridge way Centre (UNZA).Clinical Officer at UNZA clinic, Zambia. \\ ${ }^{4}$ Senior lecturer at the University of Zambia, assistant director at Chalimbana University, researcher and \\ consultant in literacy and language issues in Zambia. \\ *Corresponding Author:Tembo Beatrice, Graduate in Masters of Applied Linguistics from UNZA, \\ Education administrator, researcher, teacher of literacy and language in Zambia.
}

\begin{abstract}
Today, children play hide and seek, football and netball; they dance at night, wrestle amongst themselves, run around and ride bicycles. Behind these activities are the rules which make the children continue playing together and obey when a rule has been made. The aim of the study was to assess the teachers' utilization of the emergent literacy skills in the teaching of physical education in the primary schools of Lundazi district. The objectives of the study were to: assess the teachers' utilization of the emergent literacy skills in the teaching of physical education in the primary schools of Lundazi district and to establish the strategies being used by teachers to teach new topics in Physical Education in the primary schools of Lundazi district. The study adopted a qualitative approach and the sample was drawn from 4 schools that were randomly sampled using a raffle draw which comprised of 5 teachers from 4 schools who were purposively sampled. This totalled up to 20 teachers teaching from grades one up to grade four. Data collection was done using class observation, focus group discussion guide and an interview guide and data was analysed thematically. The findings were that the study established that children entered school with the social knowledge which they acquired from the games and activities they played and enjoyed. The social knowledge according to this study included the cordial interaction amongst children, which enabled them continue playing together despite having minor differences. Teachers used this knowledge to make learners form groups and learn from each other as brothers and sisters in harmony. Teachers established that they used a variety of teaching techniques so that learners could learn the new knowledge and skills in a PE class. Learners had knowledge of different activities and games which they played at home and in school. These games and activities equipped the learners with athletic, rhythmic and manipulative knowledge, social, hygienic, accuracy, numeracy and critical thinking skills which teachers used in their teaching of PE to Grade One in primary schools. It can be recommended that teachers should be encouraged by their superiors to develop a positive attitude towards the teaching of PE in schools. This would help learners continue acquiring the different literacies, values and attitudes which are endowed in PE activities. This can be enhanced through CPDs and teacher group meetings (TGMs). Teachers should also be encouraged to reflect different traditional games in the schemes and records of work.
\end{abstract}

Keywords:Teacher, emergent literacy skills, physical education.

\section{INTRODUCTION}

The missionaries utilised the traditional games they found in the various communities by bringing them into the school system. This they did so as to motivate children and other members of the community to come for lessons. Carmody (2002) notes that the children in the early schools played different games after attending formal education classes. This was a way of indirectly making the children keep coming to school, as well as keeping them there. The knowledge which the children came with to school was used as scaffold by the teachers in the introduction of western education. Mwondela (1972) noted that the Christian Mission in Many Lands (CMML) taught hygiene among 
the Luvale and Lunda in North-Western Province because it was part of the community education around which the tribal norms centred.

The Roman Catholic missionaries in their schools in northern Zambia taught fishing and its better methods (Snelson, 1978). This was because the Bemba community was endowed with fish, which needed preservation. The idea of bringing the local curriculum into their new schools was to encourage the communities to appreciate and accept the new forms of education. The whites or teachers used this teaching strategy indirectly to introduce, among other learning areas, swimming and canoeing to the community.

Today, children play hide and seek, football and netball; they dance at night, wrestle amongst themselves, run around and ride bicycles. Behind these activities are the rules which make the children continue playing together and obeying when a rule has been obligated. Children control themselves in games without a referee and no fights are recorded. They also learn obedience through coordination and develop muscles to continue playing these games. It is expected that the knowledge and skills children develop in the school during PE lessons will be utilised by them, parents and teachers to make society a better socio-cultural environment for the child.

\section{OVERVIEW OFLITERATURE}

\subsection{The Teachers' Utilization of the Different Emergent Literacy Skills in the Teaching of PE}

The teacher's knowledge regarding the significance of emergent literacy in their teaching of Physical Education was cardinal. This was because the children's potential should be enhanced by the teacher through appropriate activities facilitated by a conducive learning and teaching environment. John Laid noted that learning was building mental model structures in a human mind. Mental models are knowledge pieces which join each other to make a block of knowledge, (Munsaka and Matafwali, 2013). To this effect, the teacher in the education system was supposed to be an assembler of these pieces of knowledge into bigger blocks through interactive activities. The teaching of Physical Education is an inductive process of teaching from known to unknown (Dickinson, 2001). This means that teachers should be knowledgeable of their teaching content so that they could help the children acquire the much needed knowledge from the school environment.

Every culture has its own established physical activities, which the elders transmit from one generation to another. Schools adopt some physical activities which children know and then use the known knowledge to learn what is not known, Morrison (1965). From the definitions given, it can be concluded that children come to school with the emergent literacy developed through some physical play activities they engage in their environment. What was not clear was how the teachers were utilising this knowledge in their teaching of Physical Education in class.

In a study entitled 'Emergent literacy practices among children of 2 to 6 years in Mwense District of Zambia,' by Kaunda (2012), a series of traditional games and plays were found to be linked to the literacy practices. Using the observation sheet, he found that children were knowledgeable in their traditional games, plays and other activities they involved themselves in. They knew the pros and cons of the traditional activities; hence, they grew up to be responsible people in that given culture. The PE syllabus in Zambia was developed from the Zambian traditional games, plays and activities which were found in the Zambian society. The teachers in school, from such a perspective, used the traditionally blended knowledge to teach PE in the formal schools of Zambia. It was not clear in this context how the teachers were using the emergent literacy skills children came with to a Physical Education class in the teaching of PE to Grade One children in the Zambian schools.

With regard to games and organised play which children engaged in before they entered school, research in Zambia indicated that a number of children entered school with enough knowledge in various games. A study conducted by Kaunda (2012) found that children entered school with emergent literacy in various traditional games. These included; amina, wider, de mama, ichiyenga, isolo and kubuta among others. This demonstrated that Zambian children entered school with emergent literacy on various rules of different games and how they were executed. These games are all components found in the PE curriculum for primary schools and to be precise, Grade One learners. How teachers were using this emergent literacy to teach PE in their PE classes was the basis of this study. 
Research showed enough evidence that children came with different emergent literacies when they came to school, literacies which needed to be developed further by the teachers in class. A study conducted by Zimba (2011) on 'emergent literacy support in early childhood education in selected preschools of Kasempa and Solwezi Districts of Zambia,' found that teachers noticed elements of emergent literacy in preschool children. However, the study revealed that the teachers did not appreciate the children's emergent literacy. This was so because the teachers did not reinforce in any way the emergent literacies the children came with to class so that they could build on it. Despite the study being biased to preschool learners, the findings were useful to Grade Ones because from preschool, children came to Grade One. If their emergent literacy was not built upon by the preschool teachers at that level, it would mean that the children would not exhibit the emergent literacy when they came to Grade One, and the teacher might find it difficult to build on it. It was for this reason that this study was conducted to establish how the teachers were using the emergent literacy children came with to the PE class in their PE lessons.

\subsection{Strategies which Teachers have put in Place to Teach New Topics in Physical Education}

A number of studies have been conducted in literacy and emergent literacy to look at how best a child gets literate, when and at what stage does a child become literate. How parents and teachers build on the knowledge children have (emergent literacy) is what is known as scaffolding in a layman's language. According to Vygotsky (1978), scaffolding means providing the support children need to reach a slightly higher level of skill giving them opportunities to build on and extend their current skills.

In addition, Marllet and Gordon (2004) in their study on the use of alternative texts in PE recommended that those responsible for planning teacher preparation programs at colleges and universities need to begin (or continue) the task of preparing pre-service PE teachers to view physical education as a thinking subject and to prepare enriching lessons that integrate alternative texts and activities with that curriculum. The Zambian government realises the significance of teachers scaffolding on the physical education knowledge which children come with to class. MOE, (2012:7) writes that

Through PE, learners acquire the knowledge, life skills, right attitudes and values towards the pursuit of a lifelong physically active and healthy lifestyle.

From the traditional games which children play in the local compounds, they learn positive and negative attitudes and knowledge which needs to be developed at higher level by the teachers when they come to school.

Vygotsky and his social constructivism theory said that children learnt certain tasks with their elders' guidance. He thought that children were capable of fulfilling certain tasks alone while other tasks could be fulfilled with the guidance of parents and older people in the social environment; and he referred to this process as ZPD. He defined the zone of proximal development (ZPD) as:

The distance between the actual development level as determined by independent problemsolving and the level of potential development through problem-solving under adult guidance or in collaboration with more capable peers, (Vygotsky 1978:86).

In the view of Kakuwa (2005), traditional games and other activities which are in the Zambian communities have already-made rules and have unknown authors. These games have been transmitted from one generation to another, representing the cultural institutions of a certain society. From this idea, it was common knowledge that children come to a Physical Education class with the idea that the activities they were to learn had their own rules. It was not clear, however, how the teachers were using this knowledge children were coming to the PE class with to introduce new activities and build on them.

Children entered formal school with different emergent literacies in Physical Education from their traditionally blended games. Kakuwa, (2005: viii) observed that, "Traditional games have cultural, socialisational, psychological, educational, mental hygienic and many other aspects and functions in human life." Children came with the knowledge that they made friendship through games and that they had to play as a team if they were to win. They also came with the knowledge that when a friend 
was injured, play should be stopped and everyone should be concerned and attend to such a friend. First aid knowledge came in at this point. A well-known researcher in sports, (Strickland, 1989) in one of her studies proposed that teachers should concentrate on developing and improving on the knowledge of what children and their society had. She further suggested that there was need to create a safe, child-centred classroom environment, and have materials available for all children to use. The teacher's involvement in the making of the child's environment to be as conducive and safe, if not a better place, as the learners' home was questionable in the Zambian schools. It was then relevant to investigate how the teachers were using the knowledge children came within class to develop them physically, socially, and psychologically (including many other aspects and functions of Physical Education) through the formal schools.

\subsection{Aim}

The aim of the study was to assess the teachers' utilization of the emergent literacy skills in the teaching of physical education in the primary schools of Lundazi district.

\subsection{Objectives of the Study}

- To assess the teachers' utilization of the emergent literacy skills in the teaching of physical education in the primary schools of Lundazi district

- To establish the strategies being used by teachers to teach new topics in Physical Education in the primary schools of Lundazi district

\section{MeTHOdOLOGY}

The study employed a qualitative approach in Lundazi. The sample was drawn from 4 schools who were randomly sample using a raffle draw and 5 teachers from 4 schools were purposively sampled. This totalled up to 20 teachers teaching from grades one up to grade four. Data collection was done using class observation, focus group discussion guide and an interview guide and data was analysed thematically.

\section{FINDINGS AND DISCUSSIONS}

\subsection{The teachers' utilization of the different emergent literacy skills in the teaching of PE}

Findings from the respondents suggested that teachers have utilised the knowledge and skills that children come with to a PE class differently. The study established that children entered school with the social knowledge which they acquired from the games and activities they played and enjoyed. The social knowledge according to this study included the cordial interaction amongst children, which enabled them continue playing together despite having minor differences. Teachers used this knowledge to make learners form groups and learn from each other as brothers and sisters in harmony. A teacher mentioned that children usually injure themselves but they do not stop the activities. A female teacher was quick to mention that we apply kambishambisha to teach netball skills of dodging, quick stopping and direction changing.

A female teacher mentioned that

I also use social knowledge to tell my other learners that when we are scored it does not mean

that we have lost, we just have to work hard and equalize and probably beat them.

Children have even come to understand that cooperation was key in their success since life had ups and downs.

Other findings from respondents revealed that the athletic knowledge was also used by teachers. Athletic knowledge comprised the following activities wishu, gelegesha, shombawalowa, kambuzikalira lira, kuichava, vimbuza, muganda, gemu and bola yamalundi. Athletic knowledge is the knowledge which learners learn and hold which enables them be able to perform and play games which involve running, jumping up and down and other motor skill related activities at home or in school. This knowledge also involves the flexing of the muscles during training and play of the activities with the guidance of the given rules. Respondents said that

Learners know that every game has rules and regulations. It is interesting that bigger boys are not allowed to play and compete with the smaller ones citing that he is older than us. As a teacher, I ensure that older children make their own group and play with their own rules. 
The games for children do not have a referee yet they control themselves. Another respondent said, "As teachers, we give the learners rules on how they should conduct themselves in class and outside and they follow. So we start from what they know to what they don't know."

\section{DisCUSSION}

The findings are in agreement with Sherman (1999) whose study found that children valued play from their natural environment because it was through play that they grew mentally, physically, and develop socially acceptable behaviour by the society. Therefore, the teachers built strong relations within the classroom so that learners learn from each other socially acceptable behaviour worth displaying in the community.

The second finding revealed that children came to school with athletic knowledge. These findings are validated by Kaunda (2012) who said that teachers used the rules children came with from the traditional activities to teach new literacy skills. Children knew that they had fouled their friend; they had not scored; it was a penalty; they had conceded a goal; and they had to follow general rules. Therefore, the rules of warm up and warm down were well followed by the learners in class.

The findings are in line with Vygotsky (1978) who asserted that children develop problem solving skills from the capable peers under their guidance. Constructivist notions embrace both the cognitive development theory of Piaget and the socio-cultural theory of Vygotsky (Kaufman, 2004). Piaget's cognitive constructivism states that learners construct knowledge and understanding through experiences. Experiences enable learners to create schemas, mental models in the heads, which are changed, enlarged, and made more sophisticated through assimilation and accommodation. In the teaching of PE, teachers took advantage of the knowledge which learners had acquired like respect and observing rules of play in their social environment; and they introduced complex rules, which are internationally recognised. These included rules of fair play and timing of games as well as respecting the officials responsible. Therefore, teachers used the knowledge and skills learners came with to a PE class to teach new skills and knowledge to Grade 1 learners.

\subsection{Strategies being used by Teachers to Teach New Topics in Physical Education}

Teachers established that they used a variety of teaching techniques so that learners could learn the new knowledge and skills in a PE class. Teachers mentioned that PE was a practical subject, hence the teaching was practical. One teacher mentioned that I use demonstrations as a way of teaching new skills to the learners. He further narrated that, I first demonstrate how to run when I am teaching athletics. Running in a good posture then I ask some pupils to run in the manner I ran. The class in this case noted the errors made by the learners and explained how I ran

He further recommended demonstration to be the best teaching strategy of PE to young learners because they will see and practice what they saw. A female teacher cited group work being the strategy she employed in teaching new topic to learners in her PE class. She said that,

I put my learners in groups of different sizes and ages. Then, I demonstrate what I want them to

learn that day, be it a head stand, a forward roll or a cartwheel. In their groups, learners will

help each other to execute the new activity I have taught.

Children help each other in groups better than when the teacher is present. In fact, learners are more flexible in gymnastics than us teachers hence through groups, they demonstrate better to each other than the teacher.

Project works well in the teaching of PE in short. Another teacher said that

I sent children to make grain bags so that we can be using them for PE lessons on a Friday. By Monday, learners brought them and I used them to teach throwing in a PE class. The project method was used to teach PE in this case.

Teachers capitalised on the learners' emergent literacies which they came with from home and scaffold on it to teach new literacy skills in Physical Education. They also mentioned that they utilised the hygiene literacy they came with and taught them the importance of keeping clean and bathing after games. Such improved the hygienic conditions of the learners in schools. 


\section{Discussion}

The findings of the study are in agreement with Aschermann (2010) who found that teachers were supposed to build on the knowledge which learners came with to a class. She insisted that learning is chronological; hence it starts from lower levels of cognitive development to higher levels. Vygotsky (1978) add that children in the social environment shared social skills and the more capable learners helped the less capable learners in the learning environment. PE is a subject which requires all learners to play together and control each other in their conduct, emotions, thinking and language use. The teacher in this case ensured that learners learnt from each other the various social skills of respect, accepting defeat and self and emotional control in school and community.

Further, the finding are in agreement with Kasonde (2011) who found that teachers realised that learners sang traditional songs at home and in class as a way of learning. Kaunda (2012) also said that learners sang traditional songs which symbolised cultural transmission from one generation to another. Kakuwa (2005) mentioned that traditional songs were significant to the cultural preservation of the country and society. Teachers of PE in this case are seen as the facilitators to cultural transmission between generations; hence, the children should be encouraged to continue singing new songs from the different communities so that culture is preserved.

The other key literacy which was established in this study was the skill of hygiene. The study identified that children remembered to keep clean every time after playing and they bathed before going to school and after school. This finding is in agreement with Kakuwa and Sichela (2006) who found that hygiene was cardinal for learners to be healthy all year round. Learners should be encouraged to go beyond bathing and ensure they clean their surrounding in class and school, and clean the environment in their communities. MOE (2013) also advocates for the learners to be taught health skills in order have a healthy nation. Teachers used PE lessons to teach learners the various health-related skills so that learners could be healthy in schools and in the community. The teachers inspected the nails of the learners and consistently advised learners to bathe and wash after games, after a PE lesson and after play at home. The teachers used demonstration on how to ensure cleanliness on their body, in class and at their homes.

\section{CONCLUSION AND RECOMMENDATIONS}

\subsection{Conclusion}

In line with the objectives and research questions which guided this study, the following conclusions were drawn.

Learners had knowledge of different activities and games which they played at home and in school. These games and activities equipped the learners with athletic, rhythmic and manipulative knowledge, social, hygienic, accuracy, numeracy and critical thinking skills which teachers used in their teaching of PE to Grade One in primary schools. Through the identified literacy skills, learners learnt from each other the various social skills of respect, emotional control, accepting defeat and self-control in school and community through the activities the teacher exposed them to. This shaped a learner's character into a sportsman worth having in school and community. Learners in the various schools learnt from each other in groups, through teacher and pupil demonstration and individual work. The different knowledge and skills were shared in a social setting which was conducive for sharing.

It can be concluded that teachers scaffolded learners upon the literacies they came with differently. PE is a subject made all the learners to play together and control each other in their conduct, emotions, thinking and language use. The teacher in this case ensured that learners learnt from each other the various social skills of respect, emotional control, accepting defeat and self-control in school and community through the activities the teacher exposed them to. This shaped a learners' character into a sportsmanship worthy having in school and community. The rhythmic skills were embedded in the traditional songs and dances which learners enjoyed at home and in school. Teachers of PE in this case are seen as the facilitators to cultural transmission.

\subsection{Recommendations}

In light of the findings and conclusions, it can be recommended that teachers should be encouraged by their superiors to develop a positive attitude towards the teaching of PE in schools. This would help 
learners continue acquiring the different literacies, values and attitudes which are endowed in PE activities. This can be enhanced through CPDs and teacher group meetings (TGMs). Teachers should also be encouraged to reflect different traditional games in the schemes and records of work. The head teachers of the primary schools should ensure that they improvise the play grounds and facilities for traditional games which are found in the community to be found in school as well. This would enable learners and teachers who do not have such knowledge to learn from others and enhance cultural transmission and preservation through PE.

\section{REFERENCES}

[1] Aschernmann, J. L. (2012). Children Teaching and Learning in Peer Collaborative Interaction. Virginia. (Unpublished MA Dissertation. Virginia Polytechnic Institute).

[2] Davids, K., Button, C. and Bennett, S. J. (2007). Acquiring movement skill: A constraints led perspective. Champaign I, L: Human Kinetics Davidson, K. J. Jr. (1996). Human Development (7th ed). NJ: Prentice Hall, Inc.

[3] Kakuwa, M. (2005). Zambian Traditional Games and Activities. Oslo: GanGrafisk AS.

[4] Kakuwa, M. (2010). Physical Education 1. Lusaka: ZAOU Press.

[5] Kasonde, S. (2011). Games young children play, Skills Knowledge and Attitudes that are Foundations of Literacy. Lusaka: (Unpublished MA dissertation. University of Zambia).

[6] Ministry of Education. (2013). Education Curriculum Framework 2013. Lusaka: Curriculum Development Centre.

[7] Munsaka, E. (2011). Mastering the Psychology of Teaching and Learning. Ndola: Mission Press.

[8] Munsaka, E., and Matafwali, B. (2014).Human Development from Conception to Adolescence: Typical and A Typical Trends. Ndola: Mission Press.

[9] Mwansa, D. M. (2007).Adult Literacy Development and Practices. Lusaka: Zambian Open University.

[10] Mwanakatwe, M. J. (1987). The Growth of Education in Zambia since Independence. Lusaka: Oxford University Press.

[11] Mwondela, H. K. (1972). Chiseke cha Luvale. Lusaka: K.K. Foundation.

[12] Snelson, P. (1978). Education development in Northern Rhodesia 1883-1945. London: Longman.

[13] Vygotsky, L. S. (1978). Mind in Society the Developing of Higher Psychological Processes. London: Harvard University Press.

[14] Werner, P. and Almond, L. (1990). Models of Games Education. Journal of Physical Education Recreation and Dance, 61, 23-27.

[15] Zimba, T. M. (2011). Emergent literacy support in early childhood education in selected preschools of Kasempa and Solwezi Districts of Zambia. Lusaka: (Unpublished MA dissertation. University of Zambia).

\section{AUTHOR'S BIOGRAPHY}

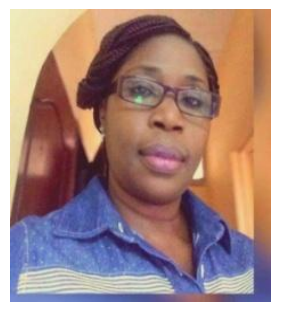

Beatrice Tembo is a school administrator and a teacher of literacy and language in Zambia. She is also a graduate of Masters of Education in Applied Linguistics at the University of Zambia. She also conducts independent research in language and literacy and Physical Education related topics in Zambia

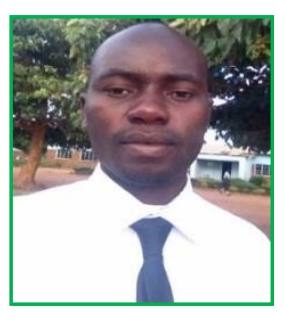

Nyimbili Friday is a $\mathrm{PhD}$ student at the University of Zambia in Applied Linguistics and a part time lecturer at University of Africa and provides research consultation. $\mathrm{He}$ is a part time editor at Lusaland Investment and a teacher of English language and literature at Chikomeni day secondary school in Lundazi district of Zambia.

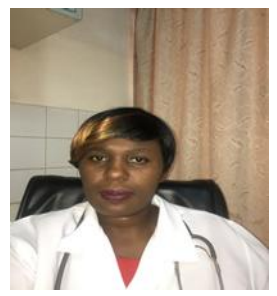

Namuyamba Mubita is a Part-Time Lecturer and researcher in the Department of Adult Education and Extension Studies at the University of Zambia. She is also a Clinical Officer at UNZA Health Services. She also provides capacity building consultancy in various organizations. 


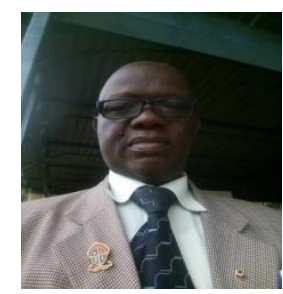

Godfrey. K. Tambuluka is Senior lecturer at the University of Zambia department of Languages and Social Sciences, Deputy Director at Chalimbana University; he is a researcher and consultant in Education related issues in Zambia and beyond.

Citation: Tembo Beatrice et.al. "Teacher Utilisation of Emergent Literacy Skills in the Teaching of Physical Education in the Primary Schools of Lundazi District". International Journal of Humanities Social Sciences and Education (IJHSSE), vol 5, no. 7, 2018, pp. 56-63. doi: http://dx.doi.org/10.20431/2349-0381.0507007.

Copyright: ( $) 2018$ Authors. This is an open-access article distributed under the terms of the Creative Commons Attribution License, which permits unrestricted use, distribution, and reproduction in any medium, provided the original author and source are credited. 